\title{
Intravesical Prostate Protrusion (IPP) versus Middle Lobe Volume on Ultrasonography in Assessing the Impact of Benign Prostatic Hyperplasia
}

\author{
Mazamaesso Tchaou ${ }^{1}$, Judith Mahunan Hounkpevi², Pihou Gbande1, Essodina Padja ${ }^{3}$, \\ Tchilabalo Kpatcha ${ }^{3}$, Ekoué Gbadoe ${ }^{1}$, Tchin Darre ${ }^{4}$, Lama Kegdigome Agoda-Koussema ${ }^{2}$ \\ ${ }^{1}$ Department of Radiology, Regional Hospital of Sokodé, Sokodé, Togo \\ ${ }^{2}$ Department of Radiology, University Hospital of Lomé, Lomé, Togo \\ ${ }^{3}$ Department of Urology, University Hospital of Lomé, Lomé, Togo \\ ${ }^{4}$ Department of Pathology, University Hospital of Lomé, Lomé, Togo \\ Email: *joseph_tchaou@yahoo.fr
}

How to cite this paper: Tchaou, M., Hounkpevi, J.M., Gbande, P., Padja, E., Kpatcha, T., Gbadoe, E., Darre, T. and Agoda-Koussema, L.K. (2020) Intravesical Prostate Protrusion (IPP) versus Middle Lobe Volume on Ultrasonography in Assessing the Impact of Benign Prostatic Hyperplasia. Open Journal of Radiology, 10, 193-202. https://doi.org/10.4236/ojrad.2020.104019

Received: October 20, 2020

Accepted: December 1, 2020

Published: December 4, 2020

Copyright $\odot 2020$ by author(s) and Scientific Research Publishing Inc. This work is licensed under the Creative Commons Attribution International License (CC BY 4.0).

http://creativecommons.org/licenses/by/4.0/

\begin{abstract}
Background: Ultrasound is the main method of exploring the prostate. In benign prostatic hyperplasia (BPH), it provides important morphological information and assesses its impact, helping to guide the treatment. Objective: To compare intravesical prostatic protrusion (IPP) and middle lobe volume by ultrasound in BPH. Method: This was a single center prospective, descriptive and analytical study, over a period of 6 months, including 95 patients, undergoing prostatic trans-abdominal ultrasound. Patients were selected by a single urologist for clinical suspicion of benign prostatic hypertrophy. The ultrasound examination was done by a single senior radiologist. Results: The mean age of the patients was $66.63 \pm 11.55$ years with ranges from 38 to 98 years. The prevalence of BPH was $76.84 \%$. The rate of patient with middle lobe protrusion was $48.42 \%$. The mean middle lobe volume was $11.29 \pm 12.90$ $\mathrm{ml}$. More than half of the patients (50.91\%) had an IPP stage 3 of. The mean bladder wall thickness was $6.08 \pm 2.58 \mathrm{~mm}$, with $50.53 \%$ being pathological. The post-voiding residue (PVR) was significant in $38.75 \%$ of patients. Renal repercussions were present in $17.89 \%$. The correlation analysis did not note a statistical link between prostate volume and quality of life score $(p>0.05)$. There was a statistically significant correlation between IPP values and quality of life score $(p=00461)$, IPSS score $(p=0.0424)$ and PVR $(p=0.0395)$. For middle lobe volume, there was a correlation with PVR $(p=0.0018)$. There was no correlation with clinical impact (quality of life score and IPSS score). Conclusion: The IPP appears to be an easy element to measure and better
\end{abstract}


than the volume of the prostate and the middle lobe in assessing the impact of $\mathrm{BPH}$.

\section{Keywords}

Benign Prostatic Hyperplasia, Ultrasonography, Intravesical Prostatic Protrusion, Middle Lobe, Togo

\section{Introduction}

Benign prostatic hyperplasia $(\mathrm{BPH})$ is the most common prostate disease. Its frequency increases with age [1]. Clinical $\mathrm{BPH}$ is a highly prevalent disease. By the age of 60 years, nearly $60 \%$ had some degree of clinical BPH [2]. Ultrasound is the main method of exploring the prostate because of its accessibility, its simplicity, non-invasive nature and its excellent cost-effectiveness. Its purpose is to provide morphological information on the prostate and to assess the importance of any impact on the upper urinary tract and to help in the selection of patients to determine the type of treatment according to the weight of the prostate, the importance of post-voiding residue (PVR) and the tissue composition of $\mathrm{BPH}$ [3].

The evaluation of the volume of the middle lobe or the measurement of intravesical prostatic protrusion (IPP) participates in the assessment of the impact of BPH. Many studies have shown that ultrasonography by assessing IPP can be used to assess the repercussion of $\mathrm{BPH}$ on the urinary tract and on the quality of life (QoL) [4] [5]. But in practice, it is rather the volume of the middle lobe that is assessed. The aim of this study was to compare the correlations with clinical and ultrasound effects of IPP and the volume of the middle lobe on ultrasound in BPH.

\section{Material and Method}

This was a prospective, descriptive and analytical study, over a period of 6 months, at the Sylvanus Olympio teaching hospital of Lomé, TOGO. The study concerned the trans-abdominal ultrasonography (TAUS) of IPP and middle lobe volume in a consecutive series of patients clinically suspected of having $\mathrm{BPH}$. Ninety-five patients were included in the study. They were selected by an urologist for clinical suspicion. Those with neurological history, confirmed prostate cancer, lower urinary tract surgery, and urinary catheter or with a parietal or intraluminal bladder lesion were excluded. Ultrasound examinations of the prostate were carried out by a single radiologist, using a $3.5 \mathrm{MHz}$ convex probe. The variables studied were: age, International Score of Prostatic Symptoms (IPSS), QoLscore, ultrasound findings (prostate volume, middle lobe volume, IPP measurement (Figure 1), bladder wall thickness, PVR volume, and dilation of renal excretory cavities). The prostate volume was considered normal when it was less than $30 \mathrm{ml}$, the bladder wall was normal if its thickness was less than $2 \mathrm{~mm}$ and the PVR considered significant if greater than $50 \mathrm{ml}$. 


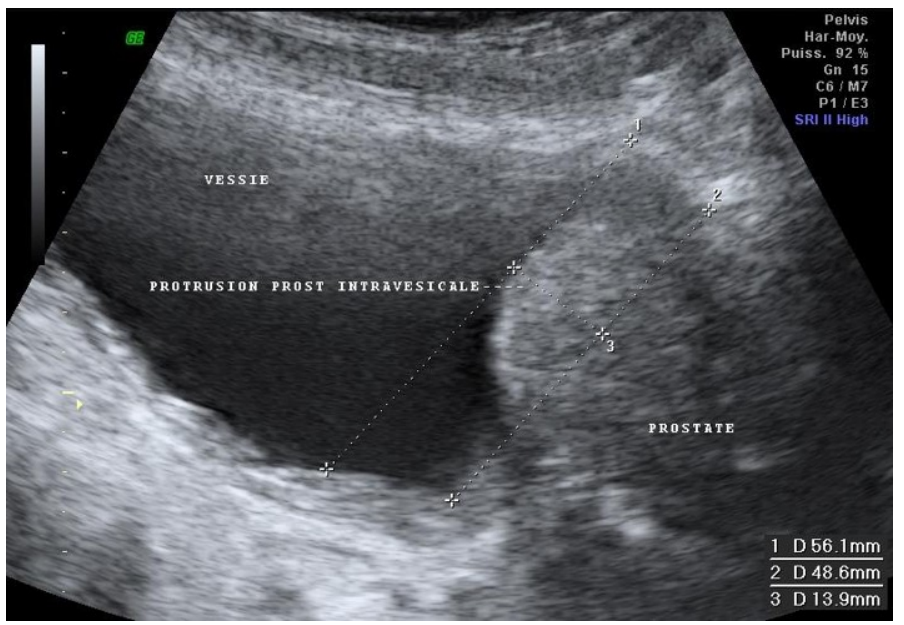

Figure 1. Trans-abdominal ultrasonography image showing the method of measurement of the IPP.

Data analysis was performed with R Studio software version 3.4.2 including the descriptive analysis of the population and the benchmarking analysis. For the benchmarking analysis, Pearson's Chi-square test or Fisher's exact test were used for qualitative variables and Student's test for quantitative variables. The p-value considered was 0.05 .

\section{Results}

\subsection{Epidemiological and Clinical Data}

The mean age of the patients was $66.63 \pm 11.55$ years with ranges from 38 to 98 years.

Table 1 summarizes the distribution of patients according to the value ranges of the IPSS and the quality of life scores.

\subsection{Trans-Abdominal Ultrasonography (TAUS) Data}

On TAUS, 73 (76.84\%) patients had an enlargement of the prostate, greater than $30 \mathrm{ml}$. A middle lobe was noted in 55 patients, achieving a prevalence of $57.89 \%$ in patient with clinical suspicion of BPH. The mean middle lobe volume was $11.29 \pm 12.90 \mathrm{ml}$ (range $1-64 \mathrm{ml}$ ).

For the 55 patients, the mean of IPP was $14.85 \pm 9.10 \mathrm{~mm}$ (range $1-38 \mathrm{~mm}$ ). The distribution according to stages was 2 (6.64\%) with IPP $<5 \mathrm{~mm}$ (stage 1), 25 (45.45\%) between 5 and 10 (stage 2) and 28 patients (50.91\%) with IPP > $10 \mathrm{~mm}$ (stage 3).

The mean of bladder wall thickness was $6.08 \pm 2.58 \mathrm{~mm}$ (range $2-19 \mathrm{~mm}$ ), with $50.53 \%$ being pathological ( $\geq 6 \mathrm{~mm}$ ). A PVR was noted in 80 patients, with a mean volume of $78.56 \pm 149.41 \mathrm{ml}$ (range $5-1200 \mathrm{ml})$. It was significant $(\geq 50$ $\mathrm{ml}$ ) in 31 patients (38.75\%).

An impact on the upper urinary tract, consisting of dilation of the intra-renal excretory cavities, was noted in $17.89 \%$. 
Table 1. Distribution of patients according to IPSS and quality of life scores.

\begin{tabular}{ccc}
\hline & Population & Percentage \\
\hline IPSS score & 19 & \\
$\leq 7$ & 53 & 20.00 \\
{$[7-19]$} & 23 & 55.79 \\
{$[19-35]$} & & 24.21 \\
Quality of life score due to urinary symptoms & 0 & 0.00 \\
Delighted & 4 & 4.21 \\
Pleased & 12 & 12.63 \\
Mostly Satisfied & 10 & 10.53 \\
Mixed & 15 & 15.79 \\
Mostly Dissatisfied & 26 & 27.37 \\
Unhappy & 28 & 29.47 \\
Terrible & & \\
\hline
\end{tabular}

\subsection{Analysis of Correlations}

There is no association between prostate volume and quality of life score ( $p>$ 0.05) (Table 2).

The analysis of the correlations between IPP and clinical and ultrasound variables summarized in Table 3 shows that there is a statistically significant correlation between the values of the IPP and QoL score $(p=00461)$, the IPSS score $(p=0.0424)$ and PVR $(p=0.0395)$.

The correlation of the IPP and the volume of the prostate studied on the scatter plot (Figure 2) shows that the two variables tend to increase at the same time. The correlation coefficient equal to 0.35 indicates that the two variables are positively correlated. The estimate of the regression line is therefore given by: IPP $=10.68+0.06 \times$ (Prostate volume) .

For the correlations between the volume of middle lobe, the clinical and ultrasound variables, it appears that there is a statistically significant difference between the volume of the middle lobe and the PVR ( $\mathrm{p}$-value $=0.0018)$ as well as with the renal impact $(p=0.0240)$ (Table 4$)$. No correlation with clinical impacts (QoL score and IPSS).

Figure 3 shows the distribution of the middle lobe volume according to the IPP. There is a linear relationship between middle lobe volume and IPP $(p<$ $0.0001)$. Both variables tend to increase at the same time. The correlation coefficient equal to 0.69 indicates that the two variables are positively correlated. The estimate of the regression line is therefore given by: IPP $=9.35+0.49 \times$ (Volume of the middle lobe). 
Table 2. Distribution of prostate volume according to quality of life score, IPSS score.

\begin{tabular}{|c|c|c|c|c|c|}
\hline \multirow{2}{*}{ Volume of the prostate $(\mathrm{ml})$} & \multicolumn{2}{|c|}{$<30(\mathrm{~N}=22)$} & \multicolumn{2}{|c|}{$\geq 30(\mathrm{~N}=73)$} & \multirow{2}{*}{$P$ value } \\
\hline & $\mathrm{n}$ & $\%$ & $\mathrm{n}$ & $\%$ & \\
\hline $\begin{array}{l}\text { Quality of life score due to } \\
\text { urinary symptoms }\end{array}$ & & & & & $0.5767^{b}$ \\
\hline Delighted & 1 & 4.54 & 3 & 4.11 & \\
\hline Pleased & 3 & 13.64 & 9 & 12.33 & \\
\hline Mostly Satisfied & 1 & 4.54 & 9 & 12.33 & \\
\hline Mixed & 6 & 27.27 & 9 & 12.33 & \\
\hline Mostly Dissatisfied & 6 & 27.27 & 20 & 27.40 & \\
\hline Unhappy & 5 & 22.73 & 23 & 31.51 & \\
\hline
\end{tabular}

$\mathrm{b}=$ Fisher exact Test.

Table 3. Distribution of IPP according to the quality of life, IPSS, PVR and renal impact.

\begin{tabular}{|c|c|c|c|c|c|c|c|}
\hline \multirow{2}{*}{$\operatorname{IPP}(\mathrm{mm})$} & \multicolumn{2}{|c|}{$<5$} & \multicolumn{2}{|c|}{$5-10$} & \multicolumn{2}{|c|}{$>10$} & \multirow{2}{*}{$P$ value } \\
\hline & $\mathrm{N}$ & $\%$ & $\mathrm{n}$ & $\%$ & $\mathrm{~N}$ & $\%$ & \\
\hline $\begin{array}{l}\text { Quality of life score due to } \\
\text { urinary symptoms }\end{array}$ & & & & & & & $0.0461^{b}$ \\
\hline Delighted & 0 & 0.00 & 2 & 8.00 & 0 & 0.00 & \\
\hline Pleased & 0 & 0.00 & 6 & 24.00 & 0 & 0.00 & \\
\hline Mostly Satisfied & 0 & 0.00 & 2 & 8.00 & 4 & 14.29 & \\
\hline Mixed & 0 & 0.00 & 4 & 16.00 & 5 & 17.86 & \\
\hline Mostly Dissatisfied & 0 & 0.00 & 7 & 28.00 & 11 & 39.29 & \\
\hline Unhappy & 2 & 100.00 & 4 & 16.00 & 8 & 28.57 & \\
\hline IPSS & & & & & & & $0.0424^{\mathrm{b}}$ \\
\hline$<8$ & 0 & 0.00 & 6 & 24.00 & 2 & 7.14 & \\
\hline $8-19$ & 0 & 0.00 & 15 & 60.00 & 15 & 53.57 & \\
\hline$>19$ & 2 & 100.00 & 4 & 16.00 & 11 & 39.29 & \\
\hline Post voiding residue (ml) & & & & & & & $0.0395^{\mathrm{b}}$ \\
\hline$<50$ & 0 & 0.00 & 15 & 68.18 & 6 & 33.33 & \\
\hline$\geq 50$ & 1 & 100.00 & 7 & 31.82 & 12 & 66.67 & \\
\hline Renal impact & & & & & & & $0.0974^{\mathrm{b}}$ \\
\hline No & 1 & 50.00 & 23 & 92.00 & 21 & 75.00 & \\
\hline Yes & 1 & 50.00 & 2 & 8.00 & 7 & 25.00 & \\
\hline
\end{tabular}

$\mathrm{b}=$ Test exact de Fisher. 
Table 4. Distribution of the mean volume of the middle lobe according to the quality of life, IPSS, PVR and renal impact.

\begin{tabular}{|c|c|c|}
\hline & $\begin{array}{l}\text { Middle lobe volume } \\
\text { Mean } \pm \text { SD }\end{array}$ & $P$ value \\
\hline $\begin{array}{l}\text { Quality of life score due to } \\
\text { urinary symptoms }\end{array}$ & & $0.4220^{\circ}$ \\
\hline Delighted & $0.90 \pm 0.99$ & \\
\hline Pleased & $4.65 \pm 4.05$ & \\
\hline Mostly Satisfied & $22.90 \pm 21.59$ & \\
\hline Mixed & $6.14 \pm 5.19$ & \\
\hline Mostly Dissatisfied & $13.24 \pm 13.97$ & \\
\hline Unhappy & $11.43 \pm 1.54$ & \\
\hline IPSS & & $0.6190^{\circ}$ \\
\hline$<8$ & $8.20 \pm 9.77$ & \\
\hline $8-19$ & $12.76 \pm 15.21$ & \\
\hline$>19$ & $10.13 \pm 9.51$ & \\
\hline Post Voiding Residue (ml) & & 0.0018 \\
\hline$<50$ & $3.56 \pm 2.50$ & \\
\hline$\geq 50$ & $12.79 \pm 11.31$ & \\
\hline Renal impact & & 0.0240 \\
\hline No & $20.60 \pm 18.84$ & \\
\hline Yes & $9.22 \pm 10.37$ & \\
\hline
\end{tabular}

$c=$ Anova

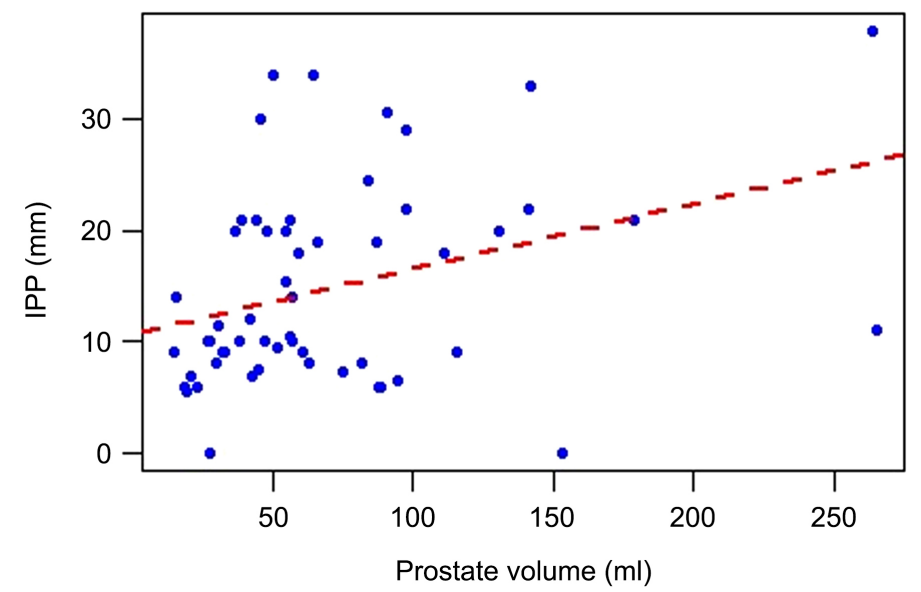

Figure 2. Scatter plot of the distribution of IPP according to prostate volume. 


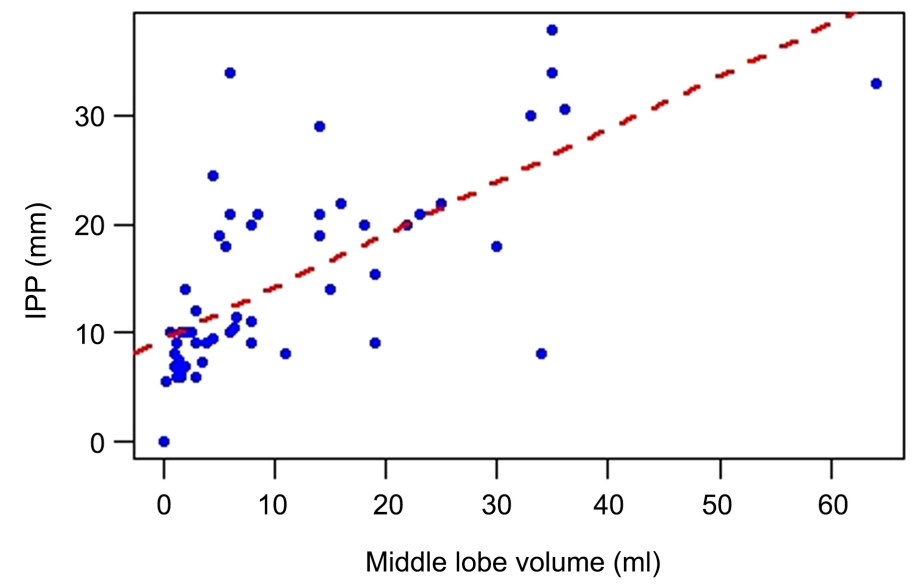

Figure 3. Scatter plot of the distribution of IPP according to middle lobe volume.

\section{Discussion}

\subsection{Epidemiological and Clinical Data}

Age is a known risk factor of occurrence of $\mathrm{BPH}$, in fact, $\mathrm{BPH}$ or prostatic adenoma begins around the fourth decade and does not become macroscopic until the sixth and seventh decades [2]. Our study with $66.63 \pm 11.55$ years as the mean age responds well to this constant, as do most of the studies in Togo, Africa and elsewhere in the world [5] [6] [7] [8].

The IPSS score is a symptom index for benign prostatic hyperplasia (BPH) developed and validated by a multidisciplinary measurement committee of the American Urological Association (AUA). It is a self-questionnaire including 7 questions covering frequency, nocturia, weak urinary stream, hesitancy, intermittence, incomplete emptying and urgency [9]. The mean total IPSS score of patients in our study was $14.66 \pm 8.23$; the most represented IPSS range was that of $8-19(55.79 \%)$. This is an average value close to the values found in the literature, which vary from $15 \pm 8.2$ to $18.2 \pm 5.8$ [4] [5] [8] [10].

The QoL assessment due to urinary symptoms is subjective and depends heavily on the beliefs and social representation of each patient. The proportion of patients who felt "terrible" was $29.47 \%$. Those who estimated their QoL as "mixed", "mostly dissatisfied" and "unhappy" was $83.16 \%$ while it was $54 \%$ in the series by Chia et al. in Singapore [11].

\subsection{Ultrasonography Data}

The recommendations of the various professional associations for the practice of additional examinations for $\mathrm{BPH}$ are variable. It depends on whether they are oriented towards urologists or general practitioners; whether they take into account the specific habits of each country or are intended to be international. Sometimes, such is low income countries, imaging exams of BPH are limited ultrasonography. It makes it possible to search for several elements allowing an objective evaluation of the impact of $\mathrm{BPH}$, in order to guide the therapeutic de- 
cision. It also provides the elements of disease surveillance. These elements are the prostate volume, middle lobe, bladder wall thickness, PVR and upper urinary tract impact. As for the middle lobe, we can measure its volume or measure its protrusion in the bladder, called intra-vesical prostatic protrusion (IPP). Intravesical prostatic protrusion (IPP) is defined as the protrusion of the middle lobe and/or lateral lobes of the prostate into the lumen of the bladder [12]. It is at the origin of a valve effect deforming the funnel-shaped disposition of the bladder neck, which can be the source of an obstructive symptomatology. This measurement evaluates the distance between the apex of the middle lobe and the neck of the bladder, in the mid sagittal plane, with a bladder filling between 150 and $250 \mathrm{cc}$. Grade I protrusion is $0-4.9 \mathrm{~mm}$, grade II $5-10 \mathrm{~mm}$, and grade III greater than $10 \mathrm{~mm}$ [11] [13] [14] [15]. IPP was measurable in 55 patients (57.89\%). The mean of the 55 IPP measurements was $14.85 \pm 9.10 \mathrm{~mm}$. This mean value is slightly higher than the values found by Aganovic et al. [10] in Bosnia, with $11.7 \pm 6.6 \mathrm{~mm}$ and by Agbo A.C. et al. [4] in Nigeria, with $12.9 \pm 7$ $\mathrm{mm}$. As in the series of Eze B.U. et al. [5], who had found 59.4\% IPP > 10mm, they were $50.91 \%$ classified as grade III in our study.

\subsection{Correlation Analysis}

Statistical analysis notes the existence of a linear relationship between the IPP measurements and the increase in prostate volume $(p=0.0126)$. Indeed, more the volume of the prostate increases, more the IPP becomes marked. Agbo A.C. et al. [4] in Nigeria $(p=0.002)$, Franco G et al. [8] in Italy $(p=0.01)$ also found a significant link between IPP and prostate volume.

As with prostate volume, there is a linear relationship between IPP and middle lobe volume. The correlation coefficients is 0.35 with the prostate volume and 0.69 with the volume of the middle lobe indicate positive correlations. One would then expect a similarity in the correlations with clinical variables of the impact of BPH, in particular quality of life and IPSS scores, but this is not the case. Indeed, as in the series of Agbo A.C. et al. in Nigeria [4], our study shows that there is a statistically correlation between IPP and QoL score $(p=0.0461)$. This correlation is not observed for prostate and middle lobe volumes. Eze B.U. et al. reported a significant positive correlation between IPP and QoL score, making possible the use of IPP for monitoring treatment, because a reduction in IPP indicates a significant improvement in quality of life [5]. This association is also observed for the IPSS score, whereas it does not exist with the volume of the middle lobe. It is only with PVR that the association is observed with both IPP and middle lobe volume.

These observations lead us to affirm that the measurement of IPP is the best variable in the assessment of the clinical and ultrasound impact of BPH. Lebdai S. et al. [12], affirmed that IPP was a better prognostic factor for upper urinary tract obstruction than prostatic volume. An additional argument in favor of IPP is the ease and speed of its measurement compared to the calculation of the vo- 
lume of the middle lobe which requires the measurement of three values, before the calculation of the volume.

\section{Conclusion}

Intravesical prostatic protrusion (IPP) appears to be an element that is easy to measure and better than the volume of the prostate and the middle lobe in assessing the impact on the quality of life and the quality of urination in patients with benign prostatic hyperplasia.

\section{Conflicts of Interest}

The authors declare no conflicts of interest regarding the publication of this paper.

\section{References}

[1] Espinosa, G., Esposito, R., Kazzazi, A. and Djavan, B. (2013) Vitamin D and Benign Prostatic Hyperplasia-A Review. The Canadian Journal of Urology, 20, 6820-6825.

[2] Arrighi, H.M., Metter, E.J., Guess, H.A. and Fozzard, J.L. (1991) Natural History of Benign Prostatic Hyperplasia and Risk of Prostatectomy, the Baltimore Longitudinal Study of Aging. Urology, 38, 4-8. https://doi.org/10.1016/0090-4295(91)80191-9

[3] Bastien, L., Fourcade, R.O., Makhoul, B., Meria, P. and Desgrandchamps, F. (2011) Hyperplasie Bénigne de la Prostate. EMC-Urologie, 29, 1-13. https://doi.org/10.1016/S1762-0953(11)52631-7

[4] Agbo, C.A., Ramyil, V.M., Dakum, N.K., Shuaibu, S.I., Onowa, V.E., Nabasu, L.E., et al. (2018) The Value of Intravesical Prostatic Protrusion in Evaluation of Bladder Outlet Obstruction from Benign Prostatic Enlargement in Nigeria. African Journal of Urology, 24, 342-346. https://doi.org/10.1016/j.afju.2018.11.007

[5] Eze, B.U., Mbaeri, T.U., Oranusi, K.C., Abiahu, J.A., Nwofor, A.M., Orakwe, J.C. and Mbonu, O.O. (2019) Correlation between Intravesical Prostatic Protrusion and International Prostate Symptom Score among Nigerian Men with Benign Prostatic Hyperplasia. Nigerian Journal of Clinical Practice, 22, 454-459. https://doi.org/10.4103/njcp.njcp_324_18

[6] Hossain, A.K., Alam, A.K., Habib, A.K., Rashid, M.M., Rahman, H., Islam, A.K., Jahan, M.U. (2012) Comparison between Prostate Volume and Intravesical Prostatic Protrusion in Detecting Bladder Outlet Obstruction Due to Benign Prostatic Hyperplasia. Bangladesh Medical Research Council Bulletin, 38, 14-17. https://doi.org/10.3329/bmrcb.v38i1.10446

[7] Botcho, G., Kpatcha, T.M., Tengue, K., Dossouvi, T., Sewa, E.V., Simlawo, K., et al. (2018) Morbidité et Mortalité Après Adénomectomies Prostatiques par Voie Transvésicale au CHU Kara (Togo). African Journal of Urology, 24, 353-358. https://doi.org/10.1016/j.afju.2018.01.008

[8] Franco, G., De Nunzio, C., Leonardo, C., Tubaro, A., Ciccariello, M., De Dominicis, C, et al. (2010) Ultrasound Assessment of Intravesical Prostatic Protrusion and Detrusor Wall Thickness-New Standards for Noninvasive Bladder Outlet Obstruction Diagnosis? International Brazilian Journal of Urology, 36, 766. https://doi.org/10.1590/S1677-55382010000600020

[9] Barry, M.J., Fowler, F.J., O’Leary, M.P., Bruskewitz, R.C., Holtgrewe, H.L., Mebust, 
W.K., Cockett, A.T. and The Measurement Committee of the American Urological Association (1992) The American Urological Association Symptom Index for Benign Prostatic Hyperplasia. Journal of Urology, 148, 1549-1557. https://doi.org/10.1016/S0022-5347(17)36966-5

[10] Aganovic, D., Prcic, A., Hadziosmanovic, O. and Hasanbegovic, M. (2012) Does the Combination of Intravesical Prostatic Protrusion and Bladder Outlet Obstruction Number Increase Test Accuracy According to Benign Prostatic Obstruction at the Individual Level? Acta Informatica Medica, 20, 160-166.

[11] Chia, S.J., Heng, C.T., Chan, S.P. and Foo, K.T. (2003) Correlation of Intravesical Prostatic Protrusion with Bladder Outlet Obstruction. BJU International, 91, 371-374. https://doi.org/10.1046/j.1464-410X.2003.04088.x

[12] Lebdai, S., Ammi, M., Bigot, P., Cornu, J.-N., Mathieu, R., Descazeaud, A., et al. (2014) Impact en Pratique Clinique de l'Indice de Protrusion Prostatique Intravésicale: Une Revue de la Littérature du CTMH de l'AFU. Progrès en Urologie, 24, $313-$ 318. https://doi.org/10.1016/j.purol.2013.09.009

[13] Grenier, N. and Devonec, M. (2006) Imagerie de la Prostate Normale, de l'Hyperplasie Bénigne et de la Pathologie Inflammatoire. Journal de Radiologie, 87, 165-187. https://doi.org/10.1016/S0221-0363(06)73992-0

[14] Cornud, F., Hamida, K., Hélénon, O. and Moreau, J.F. (1999) Appareil Genito-Urinaire-Cancer de la Prostate: Imagerie Endocavitaire du Cancer de la Prostate. Feuillets de Radiologie, 39, 322-337.

[15] Zhang, K.Q., Xu, Z.H., Zhang, J., Wang, H.X., Zhang, D.Q. and Shi, B.K. (2007) Clinical Significance of Intravesical Prostatic Protrusion in Patients with Benign Prostatic Enlargement. Urology, 70, 1096-1099. https://doi.org/10.1016/j.urology.2007.08.008 